\title{
Ectoparasite diversity in the eastern rock sengi (Elephantulus myurus): The effect of seasonality and host sex
}

${ }^{1}$ Dina M. Fagir, ${ }^{2,3}$ Ivan G. Horak, ${ }^{4,5}$ Eddie A. Ueckermann, ${ }^{1}$ Nigel C. Bennett and $*^{1}$ Heike Lutermann

${ }^{1}$ Mammal Research Institute, Department of Zoology and Entomology, University of Pretoria, Private Bag X20, Hatfield 0028, South Africa, '2 Department of Veterinary Tropical Diseases, Faculty of Veterinary Science, University of Pretoria, Onderstepoort, 0110 South Africa, ${ }^{3}$ Department of Zoology and Entomology, University of the Free State, Bloemfontein, 9301, ${ }^{4}$ ARC-Plant Protection Research Institute, Private Bag X134, Queenswood, Pretoria, 0121, South Africa, 5 School of Biological Sciences/Zoology, Potchefstroom University, Potchefstroom 2520, South Africa, correspondence to: hlutermann@zoology.up.ac.za

\begin{abstract}
Globally small mammals are important hosts of ectoparasite vectors of pathogens of medical, veterinary and economic importance. Insectivores are currently understudied as hosts of pathogen vectors. However, data are needed on the diversity of such vectors before we can investigate the underlying factors affecting ectoparasite distribution. Abiotic (e.g. temperature and rainfall) and biotic (e.g. host sex) factors have been identified as the main determinants of host-parasite interactions. The present study describes the ectoparasite community of insectivorous eastern rock sengis (Elephantulus myurus) in a nature reserve in the Gauteng Province, South Africa, and how it varies with season and host sex. A total of 81 sengis were examined for the presence of ticks, mites, fleas and lice between April 2010 and April 2011. The ectoparasite assemblage comprised of 11 groups of tick species, a single mite family, one louse and two flea species with ticks and mites being the most numerous ectoparasites recovered. The prevalence and/or abundance of two commonly collected ticks (Ixodes spp. and Rhipicephalus warburtoni/arnoldi) and chigger varied with season. In addition, female biased tick burdens were apparent for one ectoparasite species possibly due to reproductive investment. The mechanisms causing the observed patterns should be addressed in future studies.
\end{abstract}

Keywords: Macroscelididae, ectoparasites, seasonality, host sex

\section{Introduction}

Small mammals are hosts to numerous ectoparasite species some of which are vectors of pathogens such as Borrelia, Babesia and Anaplasma causing disease in both humans and livestock (Labuda \& Nuttall 2004; Morand \& Krasnov 2006). Understanding the factors that regulate the distribution of ectoparasites among host populations could provide management solutions for such diseases. It has frequently been observed that parasites exhibit aggregated or over-dispersed patterns on or within their hosts, i.e. the majority of parasites infest few host individuals, whereas most host individuals harbour only a few or no parasites (Wilson et al. 2001; Poulin 2007). Such aggregation patterns may be caused by a number of drivers that can be abiotic (e.g. climate) or biotic factors (e.g. host reproductive activity) acting on the parasite and/or the host (Wilson et al. 2001). Abiotic factors such as temperature and rainfall can result in seasonal variation in parasite burdens. For example, high temperatures can reduce developmental times for arthropod parasites but at the same time may increase the risk of desiccation and hence mortality when humidity is low (Marshall 1981; Needham \& Teel 1991; Benoit \& Denlinger 2010). For arthropod parasites such effects may be closely linked to the relationship between parasites and their hosts. Parasites such as ticks, which spend a substantial part of their life off-host, will be more strongly affected by climate factors than for example lice which spend their entire life cycle on their hosts (Marshall 1981; Randolph 2004; Kim 2006).

Seasonal variation in temperature and rainfall can also influence a host's exposure and 
susceptibility to parasitic infection. For example, during cold seasons resources may be limited while concurrently the energy demand for thermoregulation is high. If hosts have to increase their home range to cover their nutritional needs this may result in increased exposure to parasites during cold periods. Alternatively, but not mutually exclusive, hosts may have lower resistance to parasite during winter due to reduced resources available for parasite defence (Nelson et al. 2002; Martin et al. 2008). Parasite burdens may, however, also be increased during summer because the host diverts resources for parasite defences into reproductive activities (Altizer et al. 2006). Seasonal variation in ectoparasite burdens has been recorded by a number of studies carried out in different regions of Africa including South Africa and irrespective of whether those were carried out in summer or winter rainfall regions rainfall patterns appeared to play a major role in affecting these patterns (Fourie et al. 1992, 2005; Matthee et al. 2007; Lutermann et al. 2012a, $2012 b$ ). However, most of these studies have focused on ticks.

In addition to season, ectoparasite burdens are often influenced by the sex of the host. Sex-specific investment strategies in reproduction may account for gender biases in parasite burdens (Matthee et al. 2010; Kiffner et al. 2013). This could be due to differences in body size, behaviour and/or physiology between the sexes (Moore \& Wilson 2002; Klein 2004). Males of many mammal species are often larger than their female counterparts, as a result of intrasexual competition, and this could translate into them representing a larger resource patch for parasites (Moore \& Wilson 2002). Also, males may greatly increase their home range during mating periods concomitantly increasing their exposure to ectoparasites (Scantlebury et al. 2010; Boyer et al. 2010). Alternatively, higher levels of the male sex hormone testosterone have been shown to increase susceptibility to ectoparasites such as ticks (Hughes \& Randolph 2001), while lowered immune defences during gestation can render female mammals more susceptible to ectoparasites (Christe et al. 2000; Lutermann et al. 2012b). However, sex-biased parasite burdens are not the rule and the degree of sex-bias may differ between different ectoparasite species parasitizing the same host as well as for the same parasite on different host species (Scantlebury et al. 2010; Krasnov \& Matthee 2010; Kiffner et al. 2013).

Despite the substantial ectoparasite burdens, particularly of ticks, that insectivores may sustain, host-parasite interactions have less frequently been studied on these small mammals than on rodent hosts (Harrison et al. 2012). Sengis or elephant shrews (order Macroscelidae) are insectivores comprising 17 species with a wide distribution across the African continent (Skinner \& Chimimba 2005). No less than 27 tick species from six genera have been reported from sengis including several of veterinary and economic importance (Fourie et al. 1992, 1995, 2002, 2005; Harrison et al. 2011). In addition, the tick burden of sengis may be 100 times greater than those of sympatric rodents (Fourie et al. 1992; Harrison et al. 2011). Besides ticks, eight mite species from five genera, 12 flea species from nine genera, including the plague vector Xenopsylla brasiliensis, as well as one louse species have been collected from sengis but currently only descriptive information for these parasite taxa is available (Fourie et al. 1995; Segerman 1995; Beaucournu et al. 2003).

The Eastern rock sengis (Elephantulus myurus) is restricted to southern Africa with a distributional range from Mozambique, throughout parts of Zimbabwe, eastern Botswana and most parts of northeast South Africa and western Swaziland (Skinner \& Chimimba 2005). They prefer rocky habitats, specialise on ants and termites as food items and may be active during both the day and night with peaks at dusk and dawn (Skinner \& Chimimba 2005). Breeding takes place during the warm, wet summer (September to March) (Medger et al. 2012). They may host a variety of ectoparasites including the immature stages of at least 12 tick species belonging to seven genera (Fourie et al. 1995; Harrison et al. 2011; Horak et al. 2012). Of these no less than three species (Ixodes rubicundus, Rhipicentor nuttalli and Rhipicephalus warburtoni) have been implicated as causing paralysis in domestic animals, while $R$. warburtoni may also be infected with Anaplasma bovis (Fourie et al. 1992; Harrison et al. 2011). Rock sengis do not exhibit a sexual dimorphism and body mass was not a significant 
predictor of $R$. warburtoni burden in a previous study (Lutermann et al. 2012b). Only two flea species from two genera (Demeillonia granti and Macroscelidopsylla albertyni), one laelapid mite (Ornithonyssus capensis) and one louse species (Neolinognathus elephantuli) have been recorded for E. myurus (Fourie et al. 1995; Beaucournu et al. 2003). In contrast to ticks, the seasonal or sex-dependent patterns of abundance of the latter ectoparasite species as well as their status as disease vectors are largely unknown. The present study had two main aims: firstly to determine the ectoparasite community infesting eastern rock sengis in the summer rainfall region over an extended period and secondly, to assess the patterns of prevalence and abundance of ectoparasite species on these animals and evaluate the role of seasonality and host sex in generating these patterns.

\section{Materials and methods}

Study area and capture plots

Eastern rock sengis were sampled at Telperion/Ezemvelo Nature Reserve $\left(25^{\circ} 41^{\prime} \mathrm{S}\right.$, $28^{\circ} 56^{\prime}$ E) located on the border between Gauteng and Mpumalanga Provinces, South Africa. The reserve is approximately 11000 ha in size and the vegetation cover is described as Highveld grassland and savannah with large rocky outcrops present throughout the area (Swanepoel 2006). The reserve stocks a variety of large mammal species, including plains zebra, greater kudu, eland and waterbuck as well as smaller antelope species such as impalas. Smaller mammal on the reserve include hares, red rock rabbits and rock hyraxes, all of which may act as hosts for the adult and/or immature stages of several tick species (Walker et al. 2000). Sampling took place five times from April 2010 until April 2011 in order to cover all seasons (April/May, July/August, October/November in 2010 as well as January/February and April/May in 2011). Sixteen plots comprising eight rocky outcrops and eight grasslands were selected for the study. This procedure was, however, not followed during the first visit during which only five rocky outcrops and one grassland were sampled. Since the abundance of sengis was markedly higher on rocky outcrops only the latter were sampled during the last trip (April/May in 2011).

\section{Host species and trapping protocol}

Animals were collected using 72 Sherman traps (H. B. Sherman Traps, Inc., Tallahassee, Florida) baited with a mixture of peanut butter and oats to attract animals. Traps were set in each plot in four parallel lines, approximately $10 \mathrm{~m}$ apart and each line consisted of 18 traps placed about $10 \mathrm{~m}$ apart. Traps were set in the late afternoon (around 18:00) for four consecutive nights and checked early each morning (around 05:00). They were closed during the day to limit trap related deaths as a result of environmental exposure and bedding was provided in the traps during winter.

\section{Laboratory procedure}

Animals were removed from the traps and placed in Ziplock bags and transferred to a field laboratory where they were processed immediately. They were removed from the bags and then restrained by hand and their sex was recorded. Thereafter each sengi was carefully checked for ectoparasites with particular attention to the ear margins, legs and the base of the tail where ticks and mites aggregated (D.M. Fagir, personal observation). The rest of the body was searched by back-combing the fur for the presence of fleas and lice. Ectoparasites were removed using fine-tipped tweezers and stored in $70 \%$ ethanol for later identification to species level and counting. All sengis captured were marked with ear notches and subsequently released at their site of capture. Only the first capture of an individual during a capture period was included. Ticks were identified to species or genus level by I.G.H using descriptions provided by Theiler (1961), Arthur (1965), Walker et al. (2000) and Apanaskevich et al. (2007). Mites were identified to family level by E.U. using Krantz \& Walter (2009). Lice and fleas were identified by D.M.F with the help of an experienced taxonomist using the keys of Ledger (1980) and Segerman (1995), respectively. Mites, lice and fleas were mounted on glass slides for microscopic examination following standard techniques. The developmental stages of all parasite species encountered were recorded and counted.

\section{Data analysis}


Following Bush et al. (1997), species richness was defined as the number of ectoparasite species encountered on a host. In addition, prevalence was defined as the number of hosts infested with one or more individuals of a particular parasite species divided by the total number of hosts examined for that parasite species. Mean abundance was the total number of individuals of a parasite species collected divided by the total number of hosts investigated. The effect of seasonality on variation in the species richness, prevalence and abundance of the various ectoparasite species was examined using generalized linear models (GLMs). None of the data were normally distributed and consequently, a Poisson distribution with a loglink function was employed for species richness data and a binomial distribution with logit-link function was selected for prevalence data while a negative-binomial distribution with a log-link function was chosen for abundance data. Posthoc analyses were done with pairwise comparisons of all significant parameters using the least significant difference (LSD). Only the most prevalent parasite species (overall prevalence of $>15 \%$ ) were analysed in depth for prevalence and abundance. Only adult animals of a body mass exceeding $40 \mathrm{~g}$ were used in our analyses. Body mass did not differ significantly between the sexes (males: 64.035 $\pm 6.400 \mathrm{~g}$, females: $62.910 \pm 11.778 \mathrm{~g}, \mathrm{t}=0.567, \mathrm{df}=75$, $\mathrm{p}=0.600$ ). In contrast, body length (measured from neck to base of the tail) was significantly greater for male than female sengis (males: $80.491 \pm 7.640 \mathrm{~mm}$, females: $76.251 \pm 8.467 \mathrm{~mm}$, t-test: $\mathrm{t}=2.216, \mathrm{df}=69, \mathrm{p}=0.030$ ). Since body length is a better proxy for body size than body mass we initially included body length as covariate in these analyses. However, since this variable did not significantly affect any of the variables considered $(\mathrm{p} \geq 0.185)$, we only report the results for GLMs without body length. The prevalence of $R$. warburtoni/arnoldi was close to $100 \%$ (see results section) hence, we only carried out an analysis for the abundance of this species. All statistical analyses were conducted in IBM SPSS version 21 (IBM SPSS Statistics 21.Ink 2013). The study was approved by the animal ethics committee of the University of Pretoria (EC015-10) and permits were issued by the
Gauteng Nature Conservation Board (permit no. CPF6-0041).

\section{Results}

A total of 81 individual sengis of which 44 were males (54.3\%) and 37 females (45.7\%) were examined for ectoparasites. The number of sengis caught per trip and their sex is summarized in Table 1. We collected a total of 25497 immature ticks (no adults were recovered), 11584 mites, 62 lice and 32 fleas over the entire study period. Ticks $(68.6 \%)$ represented by far the largest proportion of ectoparasites recovered, followed by mites $(31.2 \%)$, lice and fleas (Table 2). The mean species richness observed was $2.88( \pm 0.142$, range: $0-7)$. It varied significantly with season (Wald $\chi^{2}=17.034, \mathrm{df}=4, \mathrm{p}=0.002$, Figure 1a). Post-hoc analyses showed that it was significantly greater in April 2011 compared to all other seasons $(\mathrm{p} \leq 0.034)$ but January 2011 (LSD: $p=0.424)$. In addition, species richness tended to be greater in January 2011 compared to April 2010 (LSD: $\mathrm{p}=0.055$ ) and was significantly higher in January 2011 than in October (LSD: $\mathrm{p}=0.004$, Figure 1a). None of the remaining pairwise comparisons was significant $(p \geq 0.129)$. Neither host sex (Wald $\chi^{2}=0.229, \mathrm{df}=1, \mathrm{p}=0.632$ ) nor the interaction between season and sex was significant (Wald $\chi^{2}=1.104, \mathrm{df}=4, \mathrm{p}=0.908$ ).

Ticks

A total of eleven ixodid tick species, representing four genera (Ixodes, Haemaphysalis, Rhipicentor and Rhipicephalus) were collected (Table 2). Large numbers of larvae and nymphs belonging to the Rhipicephalus pravus group of species (Walker et al. 2000) were collected. Some engorged nymphs from this group were allowed to moult to adults and these belonged to two tick species, namely Rhipicephalus warburtoni (referred to in earlier publications as Rhipicephalus near $R$. pravus and Rhipicephalus near $R$. warburtoni, Harrison et al. 2011; Lutermann et al. 2012a, 2012b), and Rhipicephalus arnoldi. The larvae and nymphs of these two species so closely resemble each other that it would have required that individual specimens had to be mounted on glass slides and examined under a light microscope to determine their separate identities, 
a procedure which was not practical considering the thousands of immature ticks involved and that many of these were semi-engorged or engorged. We have therefore chosen to pool these immature ticks as $R$. warburtoni/arnoldi. The larvae and nymphs of two Haemaphysalis (Rhipistoma) species (H. leachi and H. elliptica) were also present and as both of these species belonged to the subgenus Rhipistoma and were difficult to distinguish we have chosen to identify them as Haemaphysalis (Rhipistoma) spp. Similarly, the larvae and nymphs of two species within the genus Ixodes could only be identified with confidence to genus level, more particularly because the immature stages of several ticks within this genus in Africa have not been described (Arthur 1965). Engorged nymphs belonging to the genus Rhipicentor were allowed to moult and the ensuing adults were identified as Rhipicentor nuttalli. Ticks of the Rhipicephalus warburtoni/arnoldi grouping were the most prevalent and abundant, followed by Ixodes spp., $R$. distinctus and Rhipicentor nuttalli. (Table 2).

The mean abundance of $R$. warburtoni/arnoldi varied significantly with season (Table 3, Figure 1b). Post-hoc analyses revealed that abundance was significantly greater in October 2010 compared to July 2010 (LSD: P $=0.017$ ) and January 2011 (LSD: $P=0.012$ ). None of the other pairwise comparisons were significant $(P \geq 0.053)$. Neither host sex nor the interaction between season and sex were significant (Table 3 ).

None of the factors considered did significantly affect the prevalence of $R$. distinctus (Table 3). Similarly, the abundance of $R$. distinctus did not vary significantly with season nor was the interaction between sex and season significant (Table 3 ). In contrast, $R$. distinctus abundance was significantly greater for females $(1.11 \pm 3.26)$ than for males $(0.30 \pm$ 0.59 , Table 3).

The prevalence of Ixodes spp. varied significantly with season (Table 3, Figure 2a). Post-hoc tests showed that the prevalence of Ixodes spp. was significantly greater in April 2010 than in July 2010 (LSD: $P=0.026$ ). In addition, Ixodes spp. prevalence was significantly lower in October 2010 compared to January 2011 (LSD: $\mathrm{P}=0.001$, Figure 2a). None of the remaining comparisons between consecutive months were significant $(p \geq 0.338)$. Similarly, neither host sex nor the interaction between season and sex were significant (Table $3)$.

The mean abundance of Ixodes spp. varied significantly with season (Table 3, Figure 2b). Post-hoc analyses indicated that it was significantly higher in April 2010 compared to July 2010 (LSD: $\mathrm{P}<0.0001$ ) and significantly lower in October 2010 than in January 2011 (LSD: $\mathrm{P}<0.0001$, Figure 2b). No other comparisons between successive months were significant $(\mathrm{P} \geq 0.077)$. The interaction between season and sex was significant (Table 3, Figure 4a). Post-hoc analyses indicated that females carried a significantly greater number of Ixodes spp. in April 2010 than in July 2010 (LSD: P = 0.006) and in January 2011 than in April of the same year (LSD: $P=0.030$, Figure 4a). Abundance increased significantly from October 2010 to January 2011 (LSD: $\mathrm{P}=0.014$ ). The numbers of Ixodes spp. on male sengis decreased significantly from April 2010 to July 2010 (LSD: $\mathrm{P}=0.012$ ) but increased significantly from October 2010 to January 2011 (LSD: $\mathrm{P}=0.007$, Figure 4a). None of the remaining comparisons between consecutive months were significant $(\mathrm{P}$ $\geq 0.340$ ) for males nor were any of the comparisons between the sexes within a season significant $(\mathrm{P} \geq 0.066)$. Neither the prevalence nor the abundance of Rhipicentor nuttalli was significantly affected by any of the factors considered (Table 3 ).

\section{Mites}

Only the larval stage (chiggers) of one family of mites (Trombiculidae) was recovered. Of all sengis captured, $51(63 \%)$ were infested with chiggers, with the highest individual burden consisting of 1850 mites. The prevalence of chiggers did not vary significantly with any of the factors considered (Table 3). In contrast, chigger abundance varied significantly with season (Table 3, Figure 3). Post-hoc analyses showed that it was significantly higher in April 2010 than in July 2010 and significantly lower in October 2010 compared to January 2011 (P < 0.0001 for both comparisons, Figure 3). In addition, the chigger abundance was significantly greater in January 2011 compared 
to April 2011 (LSD: $\mathrm{P}=0.023$ ). Host sex had no significant effect on the abundance of chiggers (Table 3). However, the interaction between season and sex was significant (Table 3, Figure $4 b)$. Post-hoc analyses indicated that the chigger abundance on male sengis in April 2010 was significantly greater than in July 2010 (LSD: P = 0.002 ) and in January 2011 compared to October 2010 (LSD: $\mathrm{P}=0.005$, Figure 4b). Chigger abundance decreased significantly on females sengis from July to October 2010 (LSD: $\mathrm{P}=$ 0.003) and from January 2011 to April 2011 (LSD: $\mathrm{P}=0.036$ ). In contrast, the abundance of chiggers increased significantly from October 2010 to January 2011 (LSD: $\mathrm{P}=0.005$, Figure $4 \mathrm{~b})$. It was significantly lower for females compared to males in July (LSD: $\mathrm{P}=0.004$ ). None of the remaining pairwise comparisons was significant $(\mathrm{P} \geq 0.055)$.

\section{Lice}

A total of 62 lice were collected and all were identified as Neolinognathus elephantuli (Table $2)$. Only eight animals $(9.9 \%)$ were infested and the highest individual burden consisted of 29 lice.

\section{Fleas}

A total of 32 fleas belonging to two species namely, Demeillonia granti and Xenopsylla brasiliensis were collected from sengis in April 2011 (Table 2). Seven animals (8.6\%) were infested and the highest individual burden was 11 fleas (Table 2). A total of 29 Demeillonia granti was collected from three individuals (two females and one male) and a single Xenopsylla brasiliensis was collected from each of three females.

\section{Discussion}

The present study records considerable ectoparasite species diversity on eastern rock sengis, a widely distributed small mammal in the southern African region. This is in agreement with the findings of previous studies which indicated that eastern rock sengis were hosts for a large variety of parasite species, particularly ticks (Fourie et al. 1992, 1995, 2005; Beaucournu et al. 2003; Harrison et al. 2011). Species richness was greatest in summer possibly because the rainfall and elevated temperatures favoured a number of the ectoparasite species encountered. The 11 tick species recovered in the present study represent the largest number of species recovered from eastern rock sengis at a single locality. Sengis are amongst the preferred hosts of the immature stages of $R$. arnoldi and $R$. warburtoni, and virtually the sole hosts for the immature stages of R. nuttalli (Walker et al. 2000; Fourie et al. 2002, 2005). The prevalence of these ticks in the present study supports this fact. Sengis are also preferred hosts of the immature stages of Ixodes rubicundus, colloquially known as the Karoo paralysis tick, which was not recovered in this study. However, judging by the prevalence and abundance of the immature stages of the two Ixodes spp. that were collected, it would appear that sengis are preferred hosts for at least one Ixodes spp. The adults of $R$. warburtoni can induce paralysis in new-borne goat kids, those of $R$. nuttalli can cause paralysis in dogs, while the paralysis induced by the females of I. rubicundus has resulted in massive annual mortalities in sheep (Walker et al. 2000; Fourie et al. 2002, 2005). Hence, a better understanding of the factors driving the interaction between these tick species and sengis could provide valuable insights for disease management. The attachment rates and feeding success of the immature stages of $R$. warburtoni and Ixodes rubicundus are significantly higher on artificially infested eastern rock sengis than on similarly infested sympatric Namaqua rock mice (Micaelamys namaquensis) (Harrison et al. 2012). Sengis also appear to have little resistance to infestation by these ticks (du Toit et al. 1994; Harrison et al. 2012) highlighting the importance of this host for the population dynamics of these species.

The study site constitutes a new locality record for $R$. appendiculatus, a species of which all stages of development feed on large domestic and wild ruminants, particularly domestic cattle (Walker et al. 2000). With the exception of a single larvae collected from a four-toed sengi (Petrodromus tetradactylus) in northeastern KwaZulu-Natal (Horak et al. 2011), there are no records of $R$. appendiculatus on sengis. The presence of larvae and nymphs on sengis in this study indicates that this host-parasite relationship is possibly not rare, but had previously not been recorded because the localities at which the 
sengis were examined did not lie within the distribution range of the tick. This hypothesis is further supported by the observation that large burdens of Rhipicephalus muehlensi, one of 11 tick species within the $R$. appendiculatus species group, have been collected from four-toed sengis (Horak et al. 2011).

All stages of development of Rhipicephalus decoloratus and Rhipicephalus evertsi evertsi infest large domestic and wild ruminants as well as equids (Horak et al. 1992; Walker et al. 2000). Sympatric habitat preferences of these hosts and rock sengis in the reserve, together with a likely large pool of freeliving immature ticks, would account for the accidental infestations of a few larvae on the study species. Hyraxes are virtually the sole hosts of the adults of $R$. distinctus, with most collections coming from rock hyraxes (Procavia capensis) (Walker et al. 2000). The latter animals are plentiful on the rocky outcrops in the reserve. The immature stages of $R$. distinctus feed on murid rodents and those recovered from elephant shrews are most likely stragglers from a large population of free-living immature ticks.

The immature stages of several ticks within the Haemaphysalis (Rhipistoma) spp. infest murid rodents and sengis are hence only accidental hosts which may account for their low prevalence and abundance in the current study (Horak et al. 2005; Matthee et al. 2007; Apanaskevich et al. 2007).

The chiggers found in the current study constitute the first record of a trombiculid mite on eastern rock sengis, they may, however, be common on other sengi species (Fourie et al. 1995). We were unable to identify the species because of the lack of taxonomic expertise on this family of mites in South Africa. Trombiculidae (chiggers) are a large family with a worldwide distribution and are characterised by a low host specificity (Shatrov \& Kudryashova 2006). Only the larvae are parasitic and are known to cause skin irritations where their stylostome pierces the host tissue and they may also transmit diseases such as scrub typhus (Shatrov \& Kudryashova 2006).

Only one species of louse was found in the present study. Ledger (1980) described two species in the family Neolinognathus, $N$. elephantuli and $N$. prelautu, both of which are specific to sengis. Neolinognahtus elephantuli has also been recorded from three other sengi species (E. brachyrhynchus, E. rufescens and Petrodromys tetradactylus) (Fourie et al. 1995) but its geographical distribution, biology and life cycle remains largely unknown.

Two flea species were recovered in this study, Demeillonia granti and Xenopsylla brasiliensis. Both members of the genus Demeillonia, D. granti and D. miriamae, are known to prefer sengis as hosts (Segerman 1995). Demeillonia granti has been reported from three other sengi species (E. edwardii, $E$. rupestris and Macroscelides proboscideus) as well as the M. namaquensis, which share the same habitat (Zumpt 1966; Segerman 1995; Beaucournu et al. 2003). Fleas of the genus Xenopsylla are of medical importance as they are carriers of plague among wild rodents (Zumpt 1966; Segerman 1995). With the exception of $X$. cheopis, $X$. brasiliensis, also known as African flea, is the most widespread and efficient vector of plague in Africa. The usual host for $X$. brasiliensis is Rattus rattus but it has also been recorded from murid rodents such as Aethomys chrysophilus and Micaelamys namaquensis, both of which may occur sympatrically with the study species (Zumpt 1966; Segerman 1995). With few exceptions this flea is commonly associated with nest-using rodents (Segerman 1995). In contrast, sengis do not use nests (Skinner \& Chimimba 2005) and hence may not provide good environmental conditions for $X$. brasiliensis. Consequently, the infestation of sengis is likely accidental.

Three of the five main ectoparasite species of eastern rock sengis found in the study area showed marked seasonal patterns in prevalence and/or mean abundance. Since Acari spend most of their life cycle off-host and the risk of desiccation may be high during this time, this may be directly linked to climate factors such as the seasonal variation in rainfall and temperature (Needham \& Teel 1991; Benoit \& Denlinger 2010). For example, the seasonal abundance of $R$. warburtoni has been linked to temperature as well as rainfall and was greater during cool dry months compared to hot wet months in a sengi population in the Limpopo Province (Lutermann et al. 2012a). The seasonal pattern found in the current study appears to 
support this relationship. However, the peak in abundance of $R$. warburtoni/arnoldi in October was unexpected and may be linked to the onset of reproductive activity and the associated suppression of immune responses (Christe et al. 2000). This hypothesis is supported by a previous study in which the abundance of the immature stages of $R$. warburtoni on adult males and pregnant female eastern rock sengis was increased during the breeding season (August until March, Lutermann et al. 2012b).

It is likely that the seasonal variation in chigger abundance was also driven by increases in temperature and humidity (Marshall 1981) and due to their smaller size the risk of desiccation can be assumed to be higher for this species than for ticks. Increases in mite abundance with rainfall have previously been reported for several other mite species in South Africa irrespective of whether rainfall occurs during winter (Matthee et al. 2007; Archer et al. 2014) or summer (Viljoen et al. 2011) as in the current study. Unlike $R$. warburtoni/arnoldi the abundance of Ixodes spp. and chiggers was substantially lower in April 2010 than in April 2011. This may be a consequence of the former being much drier than the latter. The absence of marked seasonal patterns for the remaining two common tick species ( $R$. distinctus and Rhipicentor nuttalli) could be linked to their generally low abundance. Indeed, Rhipicentor nuttalli never appears to be particularly abundant on sengis in other provinces of South Africa (Fourie et al. 1992, 2005).

Sex-biases in abundance were found for three of the five most common ectoparasite species. The abundance of the Ixodes spp. and chiggers was male-biased during certain seasons. A similar bias has been reported for $I$. rubicundus in the Free State Province of South Africa (Fourie et al. 1992). Due to the lack of body size effects and the monogamous mating system of sengis we can largely exclude body or home range size as contributing factors towards the gender bias (Ribble \& Perrin 2005; Lutermann et al. 2012b). In contrast, the malebias could be explained by the increased susceptibility of males to Acari as a result of the immunosuppressive properties of testosterone (Hughes \& Randolph 2001). It is surprising however, that this was not apparent for $R$. warburtoni/arnoldi as higher R.warburtoni burdens have been recorded during the breeding season (August-March) on male sengis at other localities (Lutermann et al. 2012b). However, sex-biased parasitism is far from universal and may vary among parasite species infesting the same host as well as within the same parasite species when infesting different hosts (Scantlebury et al. 2010; Krasnov \& Matthee 2010; Kiffner et al. 2013). Unexpectedly the abundance of $R$. distinctus was female-biased and the causes for this are not immediately obvious. One potential explanation could be that pregnant females, but not breeding males, were particularly susceptible to this tick as has been shown for $R$. warburtoni (Lutermann et al. $2012 b)$. The observation that the prevalence of $R$. distinctus was greater during the breeding season $(38.3 \%)$ than during the non-breeding season $(11.8 \%)$ would support this hypothesis. However, this remains currently speculative and further studies are needed to corroborate this hypothesis.

In conclusion, E. myurus is host to a large diversity of ectoparasitic arthropods at the study locality, the majority of which are ticks. At least eight of the 15 ectoparasite species collected appear to be either specific parasites of sengis or preferentially use them as hosts. The remaining seven species are most probably accidental infestations. Three of the five most common ectoparasite species collected exhibited seasonal patterns that are likely to be linked to climatic conditions. In addition, reproductive effort may contribute to this pattern for $R$. warburtoni/arnoldi, the most prevalent and abundant species. Both male and female-biased parasite burdens were observed for several of the common species and we hypothesise that these may be linked to reproductive investment by the hosts. Future research is required to corroborate this hypothesis.

\section{Acknowledgements}

We are indebted to the management and staff of Ezemvelo/Telperion Nature Reserve for permission to collect animals in the reserve and their continuous support. The research was approved by the research ethics committee at the University of Pretoria (EC015-10).Numerous field assistants are thanked for their help in the 
field. We also thank Gauteng Nature Conservation for issuing the capture permits. DMF was supported by a doctoral grant from the Third World Organization for Women in Science (TWOWS) and the National Research Foundation (NRF). IGH, NCB and HL acknowledge funding from the University of Pretoria and the NRF. The project was supported by a DST-NRF SARChI chair for Mammal Behavioural Ecology and Physiology to NCB.

\section{References}

ALTIZER, S., DOBSON, A., HOSSEINI, P., HUDSON, P., PASCUAL, M. \& ROHANI, P. 2006. Seasonality and the dynamics of infectious diseases. Ecology Letters 9: 46784.

APANASKEVICH, D. A., HORAK, I. G. \& CAMICAS, J. L. 2007. Redescription of Haemaphysalis (Rhipistoma) elliptica (Koch, 1844), an old taxon of the Haemaphysalis (Rhipistoma) leachi group from East and southern Africa, and of Haemaphysalis (Rhipistoma) leachi (Audouin, 1826) (Ixodida, Ixodidae). Onderstepoort Journal of Veterinary Research 74: 181-208.

ARCHER, E. K., BENNETT, N. C., UECKERMANN, E. A. \& LUTERMANN, H. 2014. Ectoparasite burdens of the common mole-rat (Cryptomys hottentotus hottentotus) from the Cape Provinces of South Africa. Journal of Parasitology 100: 79-84.

ARTHUR, D. R. 1965. Ticks of the genus Ixodes in Africa. Athlone Press, University of London.

BEAUCOURNU, J.-C., HORAK, I. G. \& FOURIE, L. J. 2003. Fleas of elephant shrews (Mammalia, Macroscelididae), and a new host and locality record for Macroscelidopsylla albertyni De Meillon \& Marcus, $1958 \quad$ (Siphonaptera, Chimaeropsyllidae). Onderstepoort Journal of Veterinary Research 70: 251-253.

BENOIT, J. B. \& DENLINGER, D. L. 2010. Meeting the challenges of on-host and offhost water balance in blood-feeding arthropods. Journal of Insect Physiology 56: 1366-76. Elsevier Ltd.
BOYER, N., RÉALE, D., MARMET, J., PISANU, B. \& CHAPUIS, J.-L. 2010. Personality, space use and tick load in an introduced population of Siberian chipmunks Tamias sibiricus. Journal of Animal Ecology 79: 538-547.

BUSH, A. O., LAFFERTY, K. D., LOTZ, J. M. \& SHOSTAK, A. W. 1997. Parasitology meets ecology on its own terms: Margolis et al revisited. Journal of Parasitology 83: 575-583.

CHRISTE, P., ARLETTAZ, R. \& VOGEL, P. 2000. Variation in intensity of a parasitic mite (Spinturnix myoti) in relation to the reproductive cycle and immunocompetence of its bat host (Myotis myotis). Ecology Letters 3: 207-212.

FOURIE, L. J., HORAK, I. G. \& VAN DEN HEEVER, J. J. 1992. The relative importance of rock elephant shrews Elephantulus myurus and Namaqua rock mice Aethomys namaquensis for economically important ticks. South African Journal of Zoology 27: 108-114.

FOURIE, L. J., HORAK, I. G., KOK, D. J. \& VAN ZYL, W. 2002. Hosts, seasonal occurrence and life cycle of Rhipicentor nuttalli (Acari: Ixodidae). The Onderstepoort Journal of Veterinary Research 69: 177-87.

FOURIE, L. J., HORAK, I. G. \& WOODALL, P. F. 2005. Elephant shrews as hosts of immature ixodid ticks. The Onderstepoort Journal of Veterinary Research 72: 293301.

FOURIE, L. J., DU TOIT, J. S., KOK, D. J. \& HORAK, I. G. 1995. Arthropod parasites of elephant-shrews, with particular reference to ticks. Mammal Review 25: 31-37.

HARRISON, A., BOWN, K. J. \& HORAK, I. G. 2011. Detection of Anaplasma bovis in an undescribed tick species collected from the eastern rock sengi Elephantulus myurus. Journal of Parasitology 97: 1012-1016.

HARRISON, A., ROBB, G. N., BENNETT, N. C. \& HORAK, I. G. 2012. Differential feeding success of two paralysis-inducing ticks, Rhipicephalus warburtoni and Ixodes rubicundus on sympatric small mammal species, Elephantulus myurus and 
Micaelamys namaquensis. Veterinary Parasitology 188: 346-54. Elsevier B.V.

HORAK, I. G., FOURIE, L. J. \& BRAACK, L. E. O. 2005. Small mammals as hosts of immature ixodid ticks. Onderstepoort Journal of Veterinary Research 72: 255261.

HORAK, I. G., LUTERMANN, H., MEDGER, K., APANASKEVICH, D. A. \& MATTHEE, C. A. 2012. Natural hosts of the larvae of Nuttalliella sp. (N. namaqua?) (Acari: Nuttalliellidae). Onderstepoort Journal of Veterinary Research 79: 405.

HORAK, I. G., WELMAN, S., HALLAM, S. L., LUTERMANN, H. \& MZILIKAZI, N. 2011. Ticks of four-toed elephant shrews and Southern African hedgehogs. Onderstepoort Journal of Veterinary Research 78: 243.

HUGHES, V. L. \& RANDOLPH, S. E. 2001. Testosterone depresses innate and acquired resistance to ticks in natural rodent hosts: a force for aggregated distributions of parasites. Journal of Parasitology 87: 4954.

KIFFNER, C., STANKO, M., MORAND, S., KHOKHLOVA, I. S., SHENBROT, G. I., LAUDISOIT, A., LEIRS, H., HAWLENA, H. \& KRASNOV, B. R. 2013. Sex-biased parasitism is not universal: evidence from rodent-flea associations from three biomes. Oecologia 173: 1009-1022.

KIM, K. C. 2006. Blood-sucking lice (Anoplura) of small mammals: True parasites. In: Micromammals and Macroparasites - From evolutionary ecology to management, pp. 141-160. Springer Verlag, Tokyo.

KLEIN, S. L. 2004. Hormonal and immunological mechanisms mediating sex differences in parasite infection. Parasite Immunology 26: 2472-2464.

KRANTZ, G. W. \& WALTER, E. D. 2009. A manual of acarology (3rd edition). Texas Tech University Press, Lubbock.

KRASNOV, B. R. \& MATTHEE, S. 2010. Spatial variation in gender-biased parasitism: host-related, parasite-related and environment-related effects. Parasitology 137: 1527-1536.
LABUDA, M. \& NUTTALL, R. A. 2004. Tick-borne viruses. Parasitology 129: S221-S245.

LEDGER, J. A. 1980. The Arthropod Parasites of Vertebrates in Africa South of the Sahara. Volume IV. Phthiraptera (Insecta). South African Institute for Medical Research, Johannesburg.

LUTERMANN, H., MEDGER, K. \& HORAK, I. G. 2012a. Abiotic and biotic determinants of tick burdens in the eastern rock sengi (Elephantulus myurus). Medical and Veterinary Entomology 26: 255-262.

LUTERMANN, H., MEDGER, K. \& HORAK, I. G. 2012b. Effects of life-history traits on parasitism in a monogamous mammal, the eastern rock sengi (Elephantulus myurus). Naturwissenschaften 99: 103-110.

MARSHALL, A. G. 1981. The ecology of ectoparasitic insects. Academic Press, London.

MARTIN, L. B., WEIL, Z. M. \& NELSON, R. J. 2008. Seasonal changes in vertebrate immune activity: mediation by physiological trade-offs. Philosophical Transactions of the Royal Society of London 363: 321-39.

MATTHEE, S., HORAK, I. G., BEAUCOURNU, J.-C., DURDEN, L. A., UECKERMANN, E. A. \& MCGEOCH, M. A. 2007. Epifaunistic arthropod parasites of the four-striped mouse, Rhabdomys pumilio, in the Western Cape Province, South Africa. Journal of Parasitology 93: 47-59.

MATTHEE, S., MCGEOCH, M. A. \& KRASNOV, B. R. 2010. Parasite-specific variation and the extent of male-biased parasitism; an example with a South African rodent and ectoparasitic arthropods. Parasitology 137: 651-60.

MEDGER, K., CHIMIMBA, C. T. \& BENNETT, N. C. 2012. Seasonal reproduction in the eastern rock elephantshrew: influenced by rainfall and ambient temperature? Journal of Zoology 288: 283293.

MOORE, S. L. \& WILSON, K. 2002. Parasites as a viability cost of sexual 
selection in natural populations of mammals. Science 297: 2015-2018.

MORAND, S. \& KRASNOV, B. R. 2006. Micromammals and macroparasites from evolutionary ecology to management. In: New York, . Springer Verlag, Tokyo.

NEEDHAM, G. R. \& TEEL, P. D. 1991. Offhost physiological ecology of ixodid ticks. Annual Review of Entomology 36: 659-681. Annual Reviews 4139 El Camino Way, PO Box 10139, Palo Alto, CA 94303-0139, USA.

NELSON, R. J., DEMAS, G. E., KLEIN, S. L. \& KRIEGSFELD, L. J. 2002. Seasonal patterns of stress, immune function, and disease. In: Seasonal patterns of stress, immune function, and disease, (R. J. Nelson, G. E. Demas, S. L. Klein, and L. J. Kriegsfeld (eds)). Cambridge University Press, Cambridge, Uk.

POULIN, R. 2007. Evolutionary ecology of parasites. Princeton University Press, Princeton, NJ.

RANDOLPH, S. E. 2004. Tick ecology: processes and patterns behind the epidemiological risk posed by ixodid ticks as vectors. Parasitology 129: S37-S65.

RIBBLE, D. \& PERRIN, M. 2005. Social organization of the eastern rock elephantshrew (Elephantulus myurus): the evidence for mate guarding. Belgian Journal of Zoology 135: 167-173.

SCANTLEBURY, M., MAHER MCWILLIAMS, M., MARKS, N. J., DICK, J. T. A., EDGAR, H. \& LUTERMANN, H. 2010. Effects of lifehistory traits on parasite load in grey squirrels. Journal of Zoology 282: 246-255. Wiley Online Library.

SEGERMAN, J. 1995. Siphonatera of Southern Africa: A handbook for the Identification of Fleas. South African Institute for Medical Research, Johannesburg.

SHATROV, A. B. \& KUDRYASHOVA, N. I. 2006. Taxonomy, life cycles and the origin of parasitism in trombiculid mites. In: Micromammals and Macroparasites - From evolutionary ecology to management, (eds) S. Morand, B. R. Krasnov \& R. Poulin, pp. 119-140. Springer Verlag, Tokyo.

SKINNER, J. D. \& CHIMIMBA, C. T. 2005. The mammals of the southern African subregion. Cambridge University Press, Cambridge, Uk.

THEILER, G. 1961. A contribution to the knowledge of African Ixodidae. The genus Rhipicentor. Revue de Zoologie et de Botanique Africaines 66: 297-303.

DU TOIT, J. S., FOURIE, L. J. \& HORAK, I. G. 1994. Sequential feeding of Ixodes rubicundus on its natural host, Elephantulus myurus: effects on tick mass and on engorgement and moulting success. Onderstepoort Journal of Veterinary Research 61: 143-147.

VILJOEN, H., BENNETT, N. C., UECKERMANN, E. A. \& LUTERMANN, H. 2011. The role of host traits, season and group size on parasite burdens in a cooperative mammal. PLoS One 6: e27003. Public Library of Science.

WALKER, J. B., KEIRANS, J. E. \& HORAK, I. G. 2000. The genus Rhipicephalus (Acari, Ixodidae): a guide to the brown ticks of the world. Cambridge University Press, New York.

WILSON, K., BJØRNSTAD, O. N., DOBSON, A. P., MERLER, S., POGLAYEN, G., RANDOLPH, S. E., READ, A. F. \& SKORPING, A. 2001. Heterogeneities in macroparasite infections: patterns and processes. In: The ecology of wildlife diseases, (eds) P. J. Hudson, A. Rizzoli, B. T. Grenfell, H. Heesterbeek \& A. P. Dobson, pp. 6-44. Oxford University Press, New York.

ZUMPT, F. 1966. The arthropod parasites of vertebrates in Africa south of the Sahara. Vol. III (Insecta excl. Phthiraptera. South African Institute of Medical Research, Johannesburg. 
Figure 1 Seasonal variation in abundance $( \pm \mathrm{SE})$ of a) ectoparasite species richness and b) $R$. warburtoni/arnoldi found on eastern rock sengis in Ezemvelo/Telperion Nature Reserve.

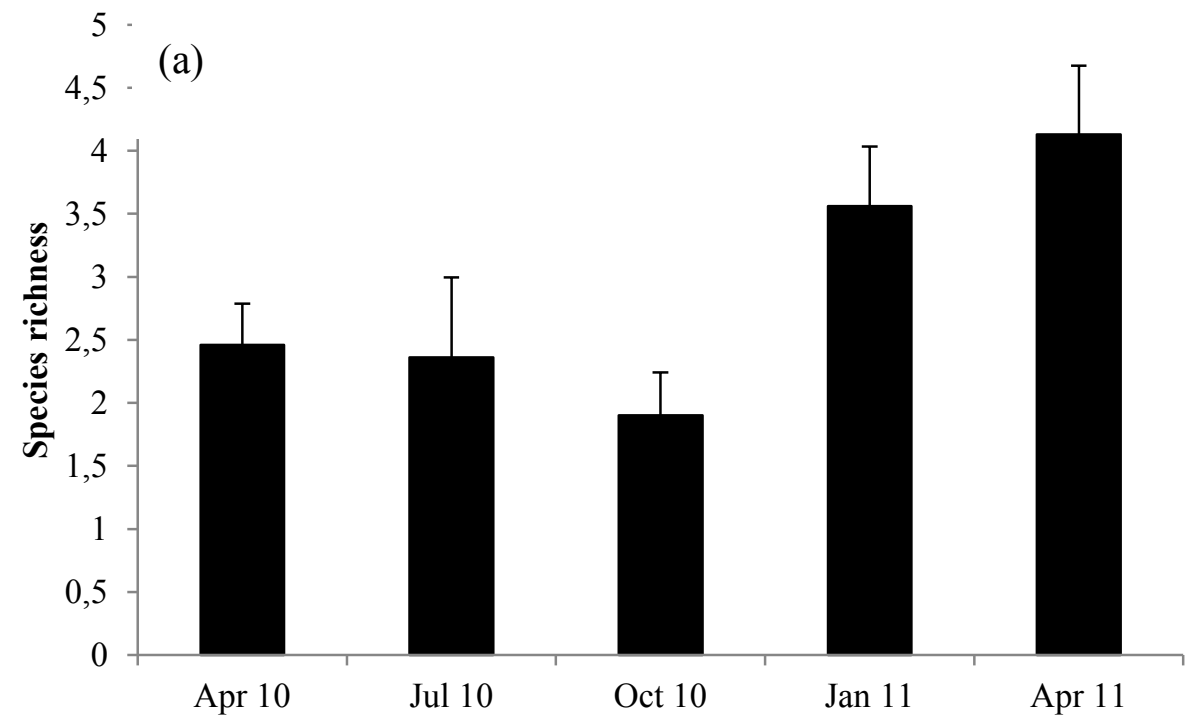

600

(b)

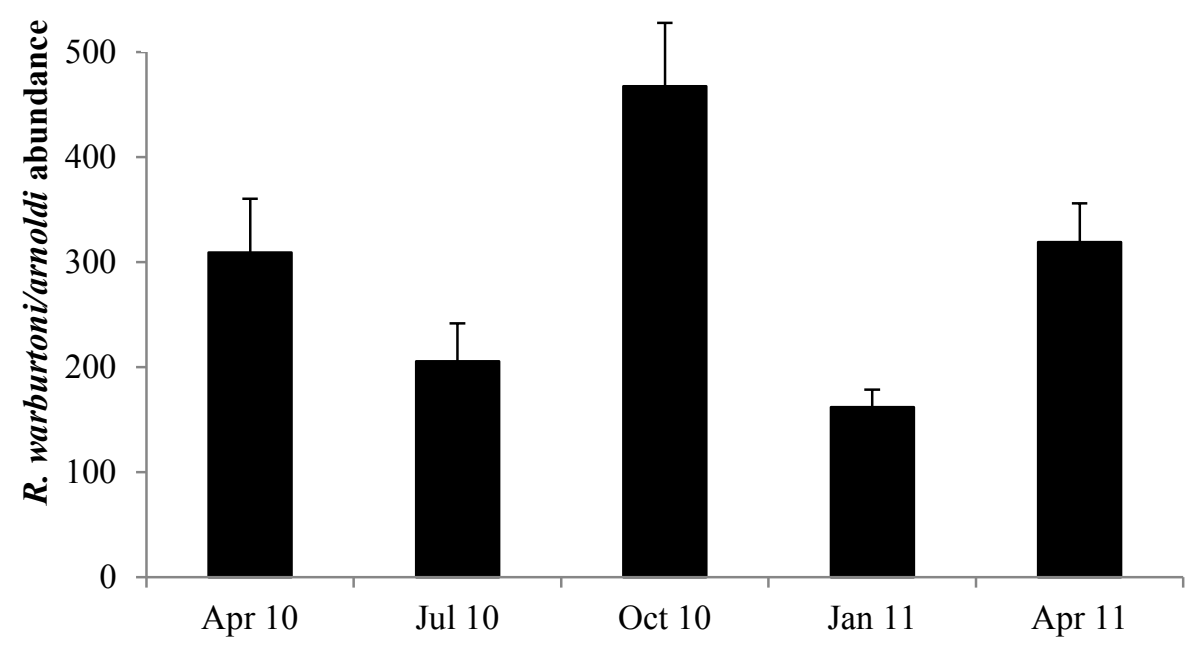


Figure 2 Seasonal variation of a) prevalence and b) mean abundance ( \pm SE) of Ixodes spp. harboured by eastern rock sengis in the Ezemvelo/Telperion Nature Reserve.

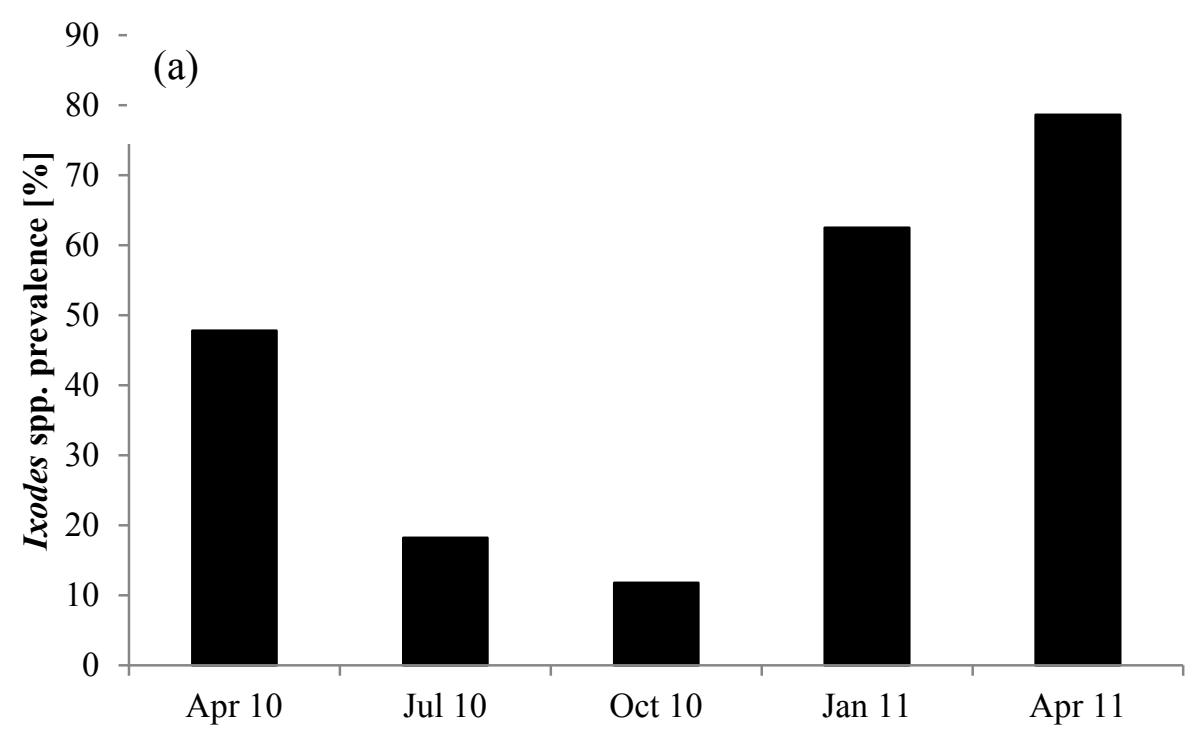

$$
30
$$

(b)
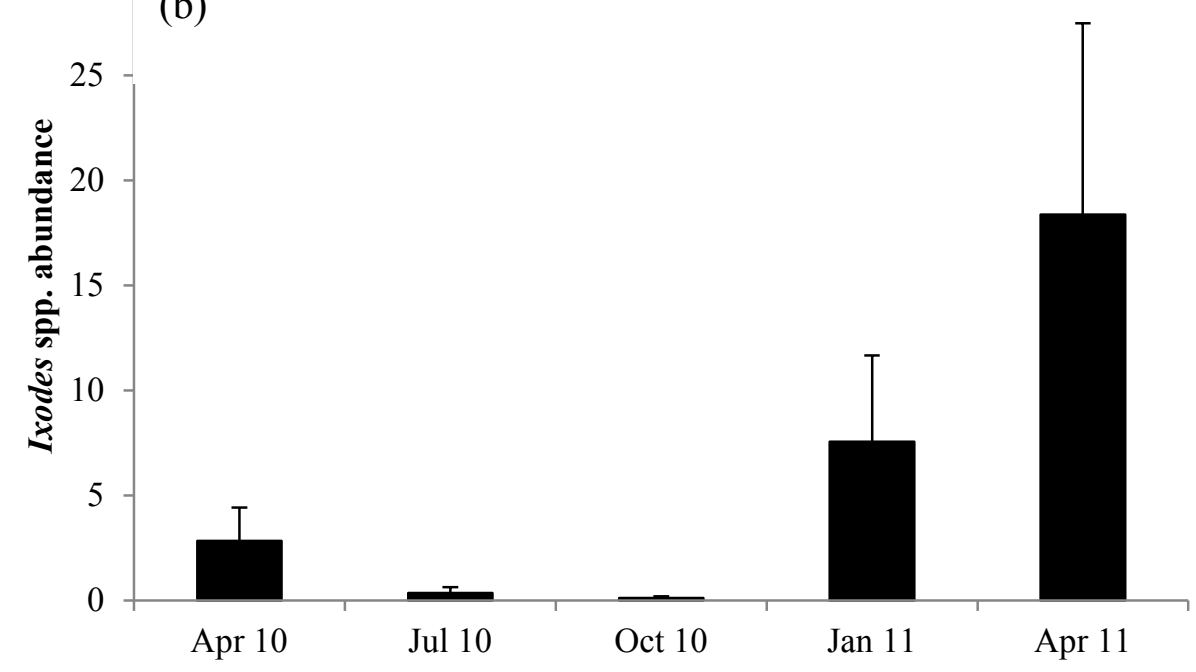
Figure 3 Seasonal variation in the mean abundance $( \pm \mathrm{SE})$ of chiggers found on eastern rock sengis in Ezemvelo/Telperion Nature Reserve.

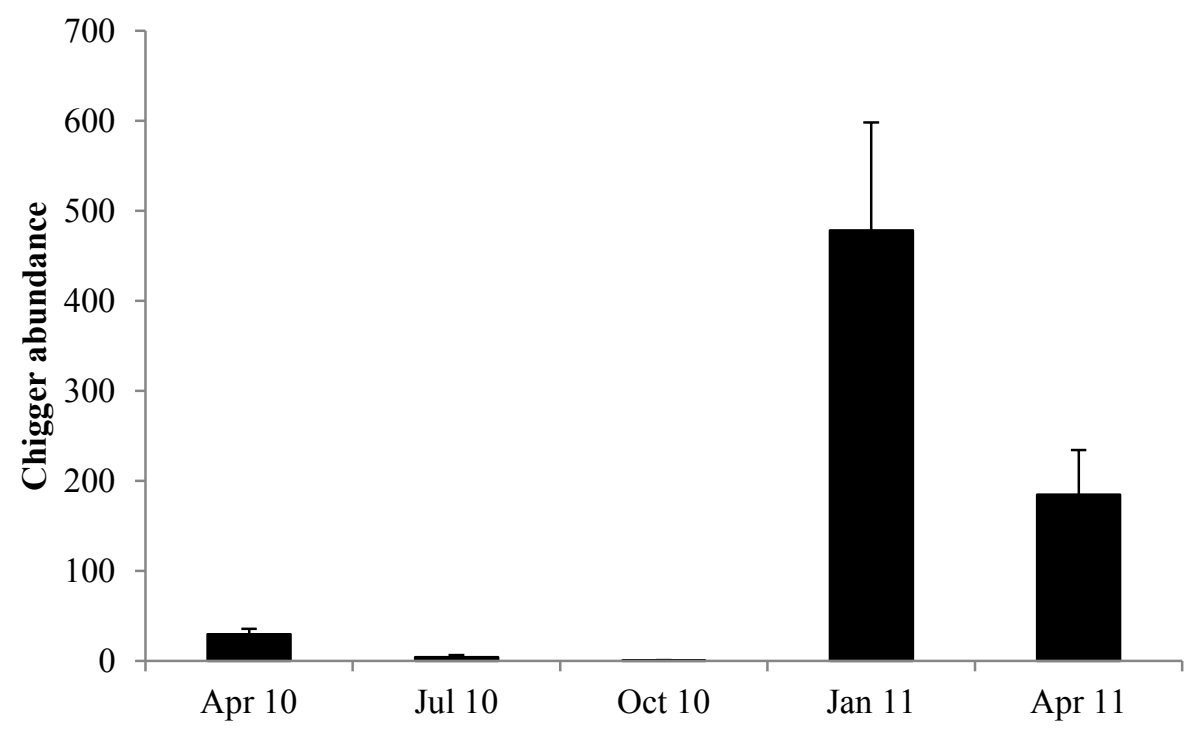


Figure 4 Variation of mean abundance ( \pm SE) with sex and season for a) Ixodes spp. and b) chiggers on eastern rock sengis in Ezemvelo/Telperion Nature Reserve. Filled bars represent males and open bars females.
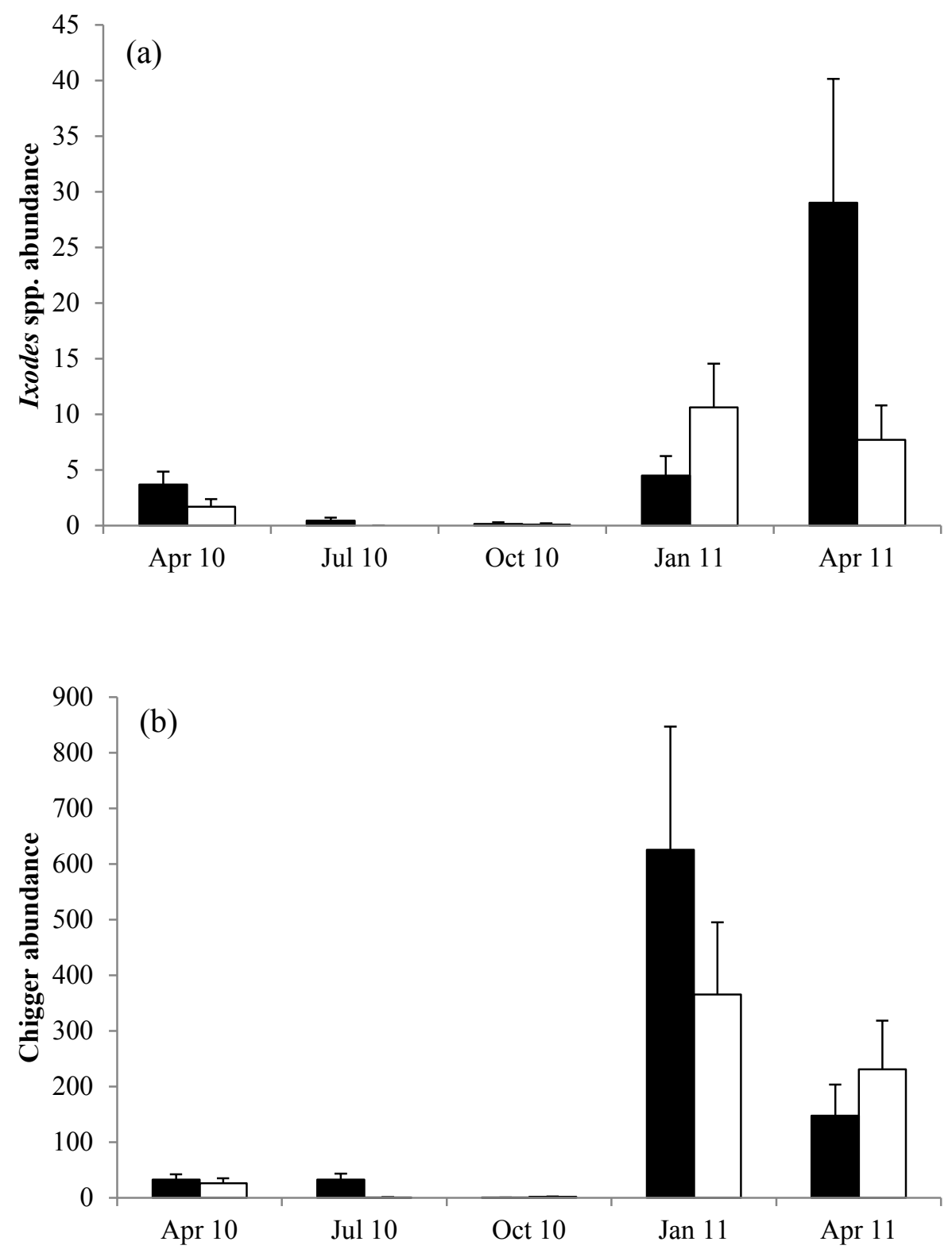
Table 1 Elephantulus myurus host individuals caught per season in the Ezemvelo/Telperion Nature Reserve.

\begin{tabular}{lll}
\hline Season & Males (mean length \pm SE mm) & Females (mean length \pm SE mm) \\
\hline April 2010 & $13(80.52 \pm 1.27)$ & $10(80.43 \pm 1.63)$ \\
July 2010 & $9(82.73 \pm 4.48)$ & $2(90.62 \pm 1.22)$ \\
October 2010 & $7(70.08 \pm 2.51)$ & $10(76.45 \pm 5.09)$ \\
January 2011 & $8(74.91 \pm 4.51)$ & $8(80.44 \pm 3.10)$ \\
April 2011 & $7(76.88 \pm 2.04)$ & $7(77.74 \pm 1.33)$ \\
\hline
\end{tabular}


Table 2. Ectoparasite species collected and their infestation parameters on Elephantulus myurus in the Ezemvelo/Telperion Nature Reserve.

\begin{tabular}{|c|c|c|c|c|}
\hline Taxon & Species & Total numbers & Prevalence (\%) & Mean abundance $( \pm \mathrm{SE})$ \\
\hline \multirow[t]{11}{*}{ Ticks } & Rhipiciphalus appendiculatus & 654 & 2.5 & $8.07( \pm 8.062)$ \\
\hline & Rhipiciphalus warburtoni/arnoldi & 24309 & 97.5 & $300.11( \pm 23.827)$ \\
\hline & Rhipiciphalus arnoldi ${ }^{*}$ & 23 & 4.9 & $0.28( \pm 0.179)$ \\
\hline & Rhipiciphalus warburtoni ${ }^{*}$ & 42 & 4.9 & $0.52( \pm 0.301)$ \\
\hline & Rhipiciphalus distinctus & 54 & 27.2 & $0.67( \pm 0.252)$ \\
\hline & Rhipiciphalus decoloratus & 2 & 2.5 & $0.02( \pm 0.017)$ \\
\hline & Rhipiciphalus evertsi evertsi & 7 & 6.2 & $0.09( \pm 0.040)$ \\
\hline & Rhipicentor nuttalli & 33 & 17.3 & $0.41( \pm 0.139)$ \\
\hline & Haemaphysalis (Rhipistoma) spp. & 11 & 9.9 & $0.14( \pm 0.052)$ \\
\hline & Ixodes spp. & 449 & 44.4 & $5.54( \pm 1.915)$ \\
\hline & Ticks total & 25497 & 98.8 & $314.78( \pm 24.0)$ \\
\hline Mites & Trombiculidae larvae (chiggers) & 11584 & 63.0 & $143.01( \pm 33.017)$ \\
\hline Lice & Neolinognathus elephantuli & 62 & 9.9 & $0.77( \pm 0.405)$ \\
\hline \multirow[t]{3}{*}{ Fleas } & Demeillonia granti & 29 & 3.7 & $0.36( \pm 0.206)$ \\
\hline & Xenopsylla brasiliensis & 3 & 3.7 & $0.04( \pm 0.021)$ \\
\hline & Fleas total & 32 & 8.6 & $0.41( \pm 0.206)$ \\
\hline
\end{tabular}

* Engorged nymphs were allowed to moult and gave rise to the adult ticks which could be unambiguously identified. 
Table 3. Results of the GLMs for prevalence and abundance of common ectoparasite species collected from Elephantulus myurus in the Ezemvelo/Telperion Nature Reserve from April 2010 until April 2011.

\begin{tabular}{|c|c|c|c|c|c|c|c|}
\hline & & \multicolumn{2}{|l|}{ Season } & \multicolumn{2}{|l|}{$\operatorname{sex}$} & \multicolumn{2}{|c|}{ Season*sex } \\
\hline & & Wald $\chi^{2}$ & $\mathbf{p}$ & Wald $\chi^{2}$ & $\mathbf{p}$ & Wald $\chi^{2}$ & $\mathbf{p}$ \\
\hline \multirow[t]{2}{*}{ R. warburtoni/arnoldi } & Prevalence & - & - & - & - & - & - \\
\hline & Abundance & 11.725 & 0.020 & 0.796 & 0.372 & 1.014 & 0.908 \\
\hline \multirow[t]{2}{*}{ R. distinctus } & Prevalence & 4.451 & 0.348 & 0.000 & 1.000 & 2.466 & 0.651 \\
\hline & Abundance & 7.162 & 0.067 & 6.662 & 0.010 & 0.757 & 0.860 \\
\hline \multirow[t]{2}{*}{ Rhipicentor nuttalli } & Prevalence & 0.194 & 0.996 & 0.000 & 1.000 & 0.546 & 0.969 \\
\hline & Abundance & 4.542 & 0.209 & 0.573 & 0.449 & 1.251 & 0.263 \\
\hline \multirow[t]{2}{*}{ Ixodes spp. } & Prevalence & 11.927 & 0.018 & 0.000 & 1.000 & 1.470 & 0.832 \\
\hline & Abundance & 65.366 & $<0.0001$ & 0.824 & 0.364 & 8.789 & 0.032 \\
\hline \multirow[t]{2}{*}{ Chiggers } & Prevalence & 6.035 & 0.197 & 0.000 & 1.000 & 0.334 & 0.988 \\
\hline & Abundance & 215.067 & $<0.0001$ & 2.438 & 0.118 & 16.284 & 0.003 \\
\hline
\end{tabular}

-: No analyses were carried out for parasites with a prevalence of $100 \%$ 